\title{
Polysaccharide from Inonotus obliquus inhibits migration and invasion in B16-F10 cells by suppressing MMP-2 and MMP-9 via downregulation of NF- $\kappa B$ signaling pathway
}

\author{
KI RIM LEE*, JONG SEOK LEE*, YOUNG RAE KIM, IN GYU SONG and EOCK KEE HONG \\ Department of Bioengineering and Technology, Kangwon National University, \\ Chuncheon, Gangwon-do 200-701, Republic of Korea
}

Received January 28, 2014; Accepted March 7, 2014

DOI: $10.3892 /$ or.2014.3103

\begin{abstract}
Polysaccharides derived from Inonotus obliquus (PIO) are known to possess multiple pharmacological activities including antitumor activity. However, the possible molecular mechanisms of these activities are unknown. In the present study, we determined the anti-metastatic potential and signaling pathways of PIO in the highly metastatic B16-F10 mouse melanoma cell line in vitro. We found that PIO suppressed the migration and invasive ability of B16-F10 cells and decreased the expression levels and activities of matrix metalloproteinase (MMP)-2 and MMP-9. In addition, PIO decreased the phosphorylation levels of extracellular signalregulated protein kinase (ERK), c-Jun N-terminal kinase (JNK) and p38 mitogen-activated protein kinase (MAPK); PIO also decreased the expression level of cyclooxygenase (COX)-2 and inhibited the nuclear translocation of nuclear factor $\kappa \mathrm{B}(\mathrm{NF}-\kappa \mathrm{B})$ in B16-F10 melanoma cells. These results suggest that $\mathrm{PIO}$ could suppress the invasion and migration of B16-F10 melanoma cells by reducing the expression levels and activities of MMP-2 and MMP-9 through suppressing MAPK, $\mathrm{COX}-2$ and $\mathrm{NF}-\kappa \mathrm{B}$ signaling pathways.
\end{abstract}

\section{Introduction}

Cancer is a major cause of human mortality worldwide. Many anticancer therapies, including chemotherapy and anticancer

Correspondence to: Professor Eock Kee Hong, Department of Bioengineering and Technology, Kangwon National University, 192-1 Hyoja-2-dong, Chuncheon, Gangwon-do 200-701, Republic of Korea E-mail: ekhong@kangwon.ac.kr

\section{${ }^{*}$ Contributed equally}

Abbreviations: ECM, extracellular matrix; ERK, extracellular signalregulated protein kinase; JNK, c-Jun N-terminal kinase; MAPK, mitogen-activated protein kinase; MMP, matrix metalloproteinase; $\mathrm{NF}-\kappa \mathrm{B}$, nuclear factor $\kappa \mathrm{B}$; COX, cyclooxygenase; Akt, protein kinase $\mathrm{B}$

Key words: Inonotus obliquus, B16-F10 melanoma cell, migration, invasion, MMPs, NF- $\mathrm{kB}$ drugs, are known to cause adverse side-effects $(1,2)$. Metastatic melanoma accounts for $\sim 80 \%$ of melanoma deaths owing to its aggressiveness and resistance to existing therapies $(3,4)$. Metastasis is a characteristic of highly malignant cancers with poor clinical outcomes. Excess extracellular matrix (ECM) degradation is a characteristic of tumor invasion and metastasis (5-7). Matrix metalloproteinases (MMPs) aid tumor cells in MMP degradation. MMPs are a group of zinc-dependent ECM degrading enzymes that facilitate the proteolysis of ECM proteins such as collagen, proteoglycan, fibronectin, elastin and laminin (8). The expression of MMP genes is primarily regulated at the transcriptional level [through AP-1 or nuclear factor $\kappa \mathrm{B}(\mathrm{NF}-\kappa \mathrm{B})$ via mitogen-activated protein kinase (MAPK) or phosphoinositide 3-kinase (PI3K)/Akt pathways] and post-transcriptional level, as well as at the protein level via their activators or inhibitors and by their cell surface localization (9-12). Recent reports on cyclooxygenase (COX)-2 expression in cancer indicated that this enzyme stimulates tumor growth, invasion and metastasis in association with MMPs (13). COX-2 is an inducible isoform that participates in pro-inflammatory responses to certain stimuli such as mitogens, cytokines and growth factors (14). These studies revealed that MMPs and their regulatory pathways may be promising targets for anti-metastatic and chemotherapeutic therapy.

Mushrooms have been used to treat various diseases including tumors. Inonotus obliquus, a traditional medicinal mushroom, has been widely used to promote health and longevity. Many studies reported that I. obliquus has many biological activities including antitumor, antimutagenic, antioxidative, antimitotic, antihyperglycemic, anti-inflammatory and immunostimulating activities (15-20). However, the anti-metastatic effect and signaling pathway mechanism of polysaccharides from I. obliquus (PIO) remain unknown. Therefore, in the present study, we investigated the antimetastatic effects and potential signaling pathways of PIO in the highly metastatic B16-F10 mouse melanoma cells in vitro.

\section{Materials and methods}

Preparation of polysaccharides from I. obliquus (PIO). Dried fruiting bodies of $I$. obliquus were purchased from a local market and ground in a blender. Milled mushroom (20 g) was 
extracted with distilled water $(600 \mathrm{ml})$ at $121^{\circ} \mathrm{C}$ for $2 \mathrm{~h}$. Extracts were centrifuged at 5,000 rpm for $20 \mathrm{~min}$, filtered through $0.45-\mu \mathrm{m}$ Whatman filter paper (\#4; Whatman, UK) to remove insoluble matter and then freeze-dried. Polysaccharides were precipitated from resuspended extracts using 75\% ethanol, collected by filtration through $0.45-\mu \mathrm{m}$ Whatman filter paper, resuspended, and dialyzed against distilled water for 5 days to remove low-molecular-weight compounds $(21,22)$.

Materials. Fetal bovine serum (FBS), penicillin G, and streptomycin were obtained from Gibco (Grand Island, NY, USA). Dulbecco's modified Eagle's medium (DMEM) was obtained from Lonza (Walkersville, MD, USA). 3-(4,5-Dimethylthiazol2-yl)-2,5-diphenyltetrazolium bromide (MTT) and isopropyl alcohol were purchased from Sigma Chemical Co. (St. Louis, MO, USA). $\beta$-actin monoclonal antibody (mAb), extracellular signal-regulated kinase (ERK) MAPK Ab, phospho-ERK MAPK Ab, stress-activated protein kinase/c-Jun N-terminal kinase (SAPK/JNK) Ab, phospho-SAPK/JNK Ab, p38 MAPK Ab, phospho-p38 MAPK Ab, COX-2 Ab, MMP-2 Ab, MMP-9 $\mathrm{Ab}$, and $\mathrm{NF}-\kappa \mathrm{B}$ p $65 \mathrm{mAb}$ were purchased from Cell Signaling Technology (Beverly, MA, USA), Santa Cruz Biotechnology (Santa Cruz, CA, USA), or BD Biosciences (San Jose, CA, USA), respectively. All other chemicals were of analytical grade.

Cell culture. The B16-F10 murine melanoma cell line was obtained from the Korea Cell Line Bank (Seoul, Korea). B16-F10 cells were cultured in DMEM supplemented with $10 \%$ heat inactivated FBS, $100 \mathrm{U} / \mathrm{ml}$ penicillin, and $100 \mu \mathrm{g} / \mathrm{ml}$ streptomycin. Cells were maintained at $37^{\circ} \mathrm{C}$ in a humidified $5 \% \mathrm{CO}_{2}$ incubator.

Cell viability. The effect of $\mathrm{PIO}$ on the viability of B16-F10 cells was measured using the MTT assay, which is based on the reduction of a tetrazolium salt by mitochondrial dehydrogenase in viable cells. Cells were pre-incubated in 12-well plates for $24 \mathrm{~h}$ at $37^{\circ} \mathrm{C}$ humidified atmosphere of $5 \% \mathrm{CO}_{2}$ incubator. Then, cells were incubated with PIO $(1-1,000 \mu \mathrm{g} / \mathrm{ml})$ for $24 \mathrm{~h}$. After incubation, cells were washed with 1X PBS to remove dead cells, and then $50 \mu \mathrm{l}$ of MTT stock solution $(2 \mathrm{mg} / \mathrm{ml}$ ) was added to each well, which was then incubated for $2 \mathrm{~h}$. After incubation, the MTT assay was performed to quantitate cellular viability. Finally, isopropyl alcohol was added to solubilize the formazan salt formed, and the amount of formazan salt was determined by measuring the absorbance at $595 \mathrm{~nm}$ using an enzyme-linked immunosorbent assay microplate reader.

Flow cytometry. The apoptotic death of tumor cells was examined using a fluorescein isothiocyanate (FITC)-labeled Annexin V/propidium iodide (PI) apoptosis detection kit (Molecular Probes, Eugene, OR, USA) according to the manufacturer's instructions. Briefly, cells were harvested by trypsinization, washed with PBS and centrifuged to collect the cell pellet. The number of cells was adjusted to $1 \times 10^{6}$ cells $/ \mathrm{ml}$. The cells were then resuspended in binding buffer $(10 \mathrm{mM}$ HEPES, $140 \mathrm{mM} \mathrm{NaCl}$, and $2.5 \mathrm{mM} \mathrm{CaCl}_{2}$, at $\mathrm{pH} 7.4$ ) and stained with FITC-labeled Annexin V and PI at room temperature for $15 \mathrm{~min}$ in the dark. Flow cytometric analysis was performed using a FACSCalibur flow cytometer (BectonDickinson, Mountain View, CA, USA) within $1 \mathrm{~h}$ after supravital staining. FITC-labeled Annexin V was analyzed using excitation and emission settings of 488 and $535 \mathrm{~nm}$, respectively. PI was analyzed using excitation and emission settings of 488 and $575 \mathrm{~nm}$, respectively. For each flow cytometer run, 10,000 cells were required. The percentages of cells were calculated using the CellQuest software (BectonDickinson). The cells in the early stages of apoptosis were Annexin V-positive and PI-negative; however, the cells in the late stages of apoptosis were both Annexin V-and PI-positive. The apoptotic index (\%) was calculated as the sum of late apoptotic cells divided for the total number of events.

Wound healing assay. The wound healing assay was performed as previously described with some modifications (23). Briefly, B16-F10 cells were grown to confluence in 6-well dishes for $24 \mathrm{~h}$ in serum-free medium (three dishes per group). The medium was replaced with serum-containing medium followed by the addition of PIO at various concentrations $(0,25$, 50 and $100 \mu \mathrm{g} / \mathrm{ml})$, and the cells in monolayer were disrupted (i.e., wounded) by scraping them with a $100-\mu 1$ micropipette tip. At the indicated times (0, 24 and $48 \mathrm{~h})$ after scraping, the cells were washed twice with PBS (pH 7.4). Finally, the cells were gently washed three times with PBS and photographed with an optical microscope at $\mathrm{x} 40$.

In vitro migration and invasion assay. The migration of B16-F10 cells was also measured by chemotactic directional migration using a 6 -well Transwell insert. The $8-\mu$ m pore filters (Corning Incorporated, Corning, NY, USA) were coated with gelatin (Sigma) and B16-F10 cells $\left(1 \times 10^{6}\right.$ cells $\left./ \mathrm{ml}\right)$ were placed in the upper chamber with or without PIO (50 or $100 \mu \mathrm{g} / \mathrm{ml}$ ) and allowed to undergo migration for $24 \mathrm{~h}$. The non-migrated cells in the upper chamber were removed with a cotton swab. The filters were stained with $2 \%$ crystal violet. Migrated cells adherent to the underside of the filter were counted and photographed using an optical microscope at $\mathrm{x} 40$. The invasion of B16-F10 cells was measured using Matrigel-coated Transwell cell culture chambers $(8-\mu \mathrm{m}$ pore size) as previously described. After the cells were cultured for $24 \mathrm{~h}$ in serumfree DMEM, they were collected, resuspended in serum-free medium, placed in the upper chamber of the Transwell insert $\left(1 \times 10^{6}\right.$ cells $\left./ \mathrm{ml}\right)$, and incubated with or without PIO (50 or $100 \mu \mathrm{g} / \mathrm{ml})$. DMEM containing 10\% FBS was placed in the lower chamber. All the cells in each treatment group were incubated for $24 \mathrm{~h}$ at $37^{\circ} \mathrm{C}$ in a humidified atmosphere with $95 \%$ air and $5 \% \mathrm{CO}_{2}$. The non-invasive cells that remained in the upper chamber were removed by wiping with a cotton swab, and the invasive cells were fixed with $4 \%$ formaldehyde in PBS and stained with $2 \%$ crystal violet in $2 \%$ ethanol. The invasive cells in the lower surface of the filter that penetrated through the Matrigel were counted and photographed using an optical microscope at $\mathrm{x} 40$ (24).

Zymography analysis. Sodium dodecyl sulfate-polyacrylamide gel electrophoresis (SDS-PAGE) substrate-embedded enzymography (zymography) was used to identify collagenase and gelatinase activities $(25,26)$. Briefly, the supernatant collected from the cell culture was resolved in $10 \%$ SDS-PAGE gels, 
which were prepared by the incorporation of gelatin $(1 \mathrm{mg} / \mathrm{ml})$ before casting. After electrophoresis, the gels were washed twice for $30 \mathrm{~min}$ in $2.5 \%$ Triton $\mathrm{X}-100$ with shaking. The gels were then incubated at $37^{\circ} \mathrm{C}$ for $24-48 \mathrm{~h}$ in reaction buffer containing $50 \mathrm{mM}$ Tris- $\mathrm{HCl}$ (pH 7.6), $10 \mathrm{mM} \mathrm{CaCl}_{2}, 150 \mathrm{mM}$ $\mathrm{NaCl}$, and $20 \%$ sodium azide, followed by staining with $0.25 \%$ Coomassie brilliant blue G-250 in 50\% methanol and $10 \%$ acetic acid for $1-2 \mathrm{~h}$. The completely stained gels were appropriately destained with $40 \%$ methanol and $10 \%$ acetic acid. The enzyme activities were evident as clear (unstained) regions against the dark background.

Western blot analysis. After treatment, the cells were washed in $1 \mathrm{X}$ PBS and lysed in lysis buffer $[10 \mathrm{mM}$ Tris- $\mathrm{HCl}(\mathrm{pH} 7.5)$, $10 \mathrm{mM} \mathrm{NaH} \mathrm{PO}_{4} / \mathrm{NaHPO}_{4}(\mathrm{pH} 7.5), 130 \mathrm{mM} \mathrm{NaCl}, 1 \%$ Triton X-100, $10 \mathrm{mM}$ NaPPi, $1 \mathrm{mM}$ phenylmethylsulfonyl fluoride, $2 \mu \mathrm{g} / \mathrm{ml}$ pepstatin A] for $30 \mathrm{~min}$ on ice. Lysates were centrifuged at $12,000 \mathrm{x}$ g for $20 \mathrm{~min}$ at $4^{\circ} \mathrm{C}$. The supernatant was collected, and its protein content was measured using a Bio-Rad protein assay kit (Bio-Rad Laboratories, Hercules, CA, USA) before analysis. The cytosolic or nuclear protein samples were loaded at $10 \mu \mathrm{g}$ of protein/lane, separated by SDS-PAGE in $10-15 \%$ gel, and transferred to NC membranes (Immun-Blot NC membrane, $0.2 \mu \mathrm{m}$; Bio-Rad Laboratories). Membranes were blocked with $1.5 \%$ skim milk in $1 \mathrm{X}$ Trisbuffered saline (TBS) containing $0.1 \%$ Tween-20 for $1 \mathrm{~h}$, and they were incubated with primary antibodies at $4^{\circ} \mathrm{C}$ overnight. Finally, the membranes were treated with horseradish peroxidase-coupled secondary antibodies for $1 \mathrm{~h}$ at $4^{\circ} \mathrm{C}$. The membranes were washed with TBS after each antibody binding reaction. The detection of each protein was performed using an enhanced chemiluminescence kit (Millipore Co., Billerica, MA, USA).

Nuclear protein extraction. Nuclear extracts were prepared by lysing nuclei in high-salt buffer supplemented with protease and phosphatase inhibitors using a nuclear extraction kit (Panomics Inc., Fremont, CA, USA) according to the manufacturer's protocol. Protein concentrations were quantified using the Bio-Rad protein assay.

Statistical analysis. Data are expressed as mean \pm standard error (SE) values, and the results were obtained from at least three independent experiments performed in triplicate. The data were analyzed using Student's t-test to evaluate significant differences. A $\mathrm{P}<0.05$ was regarded as statistically significant.

\section{Results}

Effect of PIO on viability in B16-F10 cells. To investigate the cytotoxicity of PIO in B16-F10 melanoma cells, cells were treated with PIO at various concentrations ranging from 0 to $1,000 \mu \mathrm{g} / \mathrm{ml}$ for $24 \mathrm{~h}$ and cell viability was determined by the MTT assay. We found that PIO did not significantly affect the growth of B16-F10 cells (Fig. 1A). To evaluate whether the growth-inhibitory of PIO was associated with apoptosis, a double-staining method using FITC-labeled Annexin V and PI was performed. During the early stage of apoptosis, cells display phosphatidylserine on their outer cell membranes, which is readily detectable using Annexin V. During the later

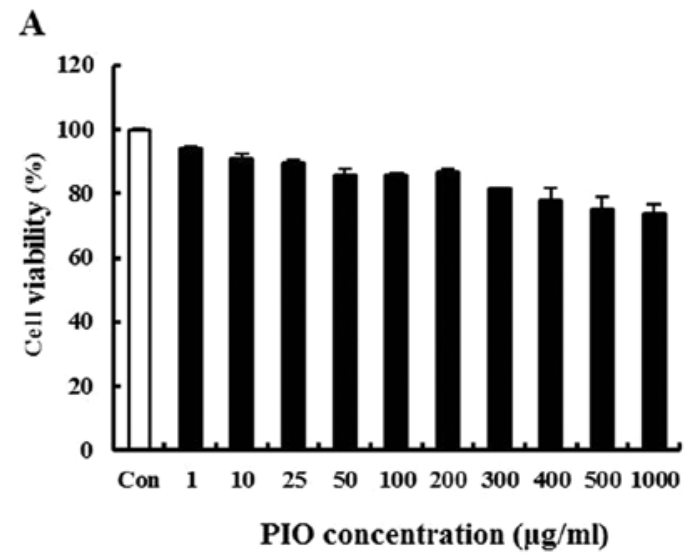

B

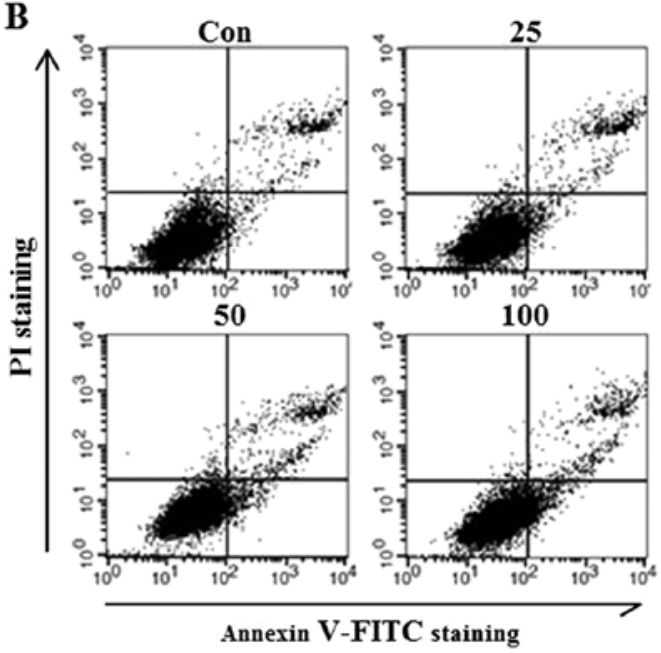

C

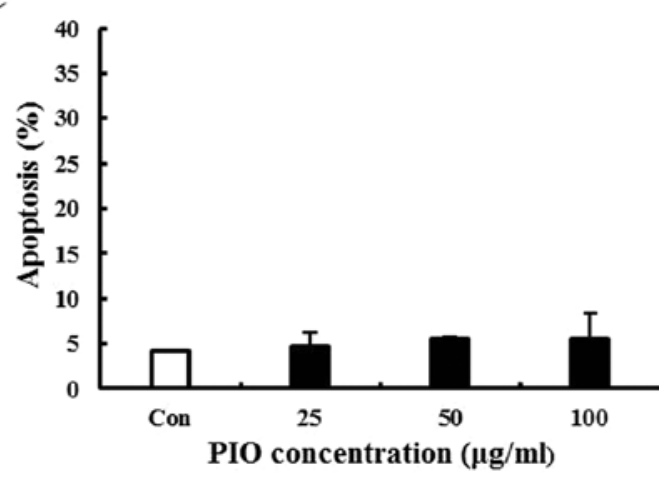

Figure 1. Effect of PIO on cell viability and apoptosis in the B16-F10 cells. (A) The B16-F10 cells were incubated with various concentrations $(0-1,000 \mu \mathrm{g} / \mathrm{ml})$ of PIO for $24 \mathrm{~h}$. (B and C) B16-F10 cells were incubated with various concentrations $(0-100 \mu \mathrm{g} / \mathrm{ml})$ of PIO for $24 \mathrm{~h}$. The number and percentage of apoptotic cells was detected by Annexin V/PI flow cytometric analysis. The data represent the means $\pm \mathrm{SE}$ of three independent experiments.

stages of apoptosis, as the plasma membrane becomes increasingly permeable, PI can move across the cell membrane to bind to cellular DNA. Double staining the cells with Annexin V and PI allowed us to detect apoptotic cells by flow cytometry. Low concentrations of PIO $(25,50$ or $100 \mu \mathrm{g} / \mathrm{ml})$ did not have an apoptotic effect on the cells (Fig. 1B and C). Therefore, these results demonstrated that $\mathrm{PIO}$ at concentrations ranging from 0 to $100 \mu \mathrm{g} / \mathrm{ml}$ did not induce cell death and apoptosis in the highly metastatic B16-F10 melanoma cell line. This concentration range was then applied in all subsequent experiments. 
A

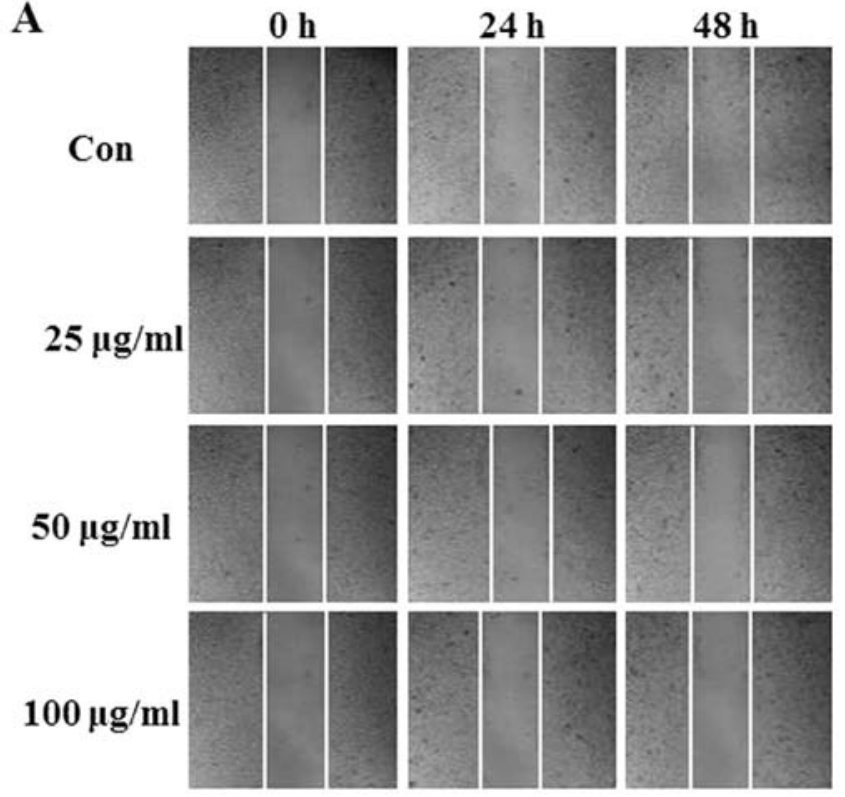

B

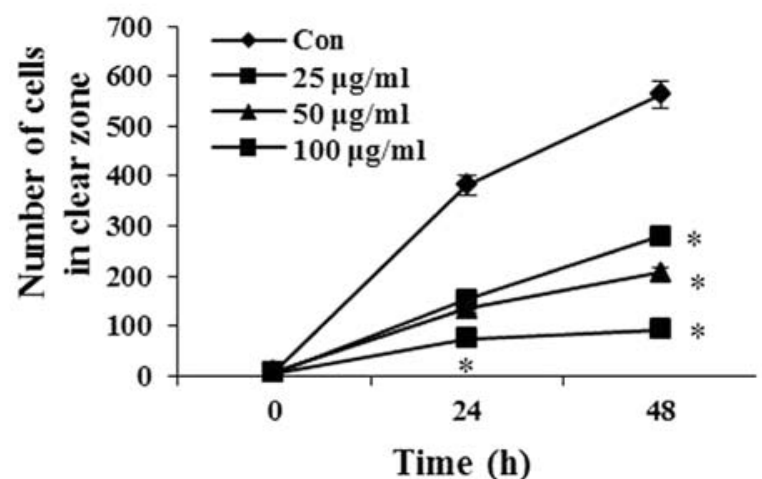

Figure 2. Effects of PIO on the motility of the B16-F10 cells. Cell mobility was determined by the wound healing assay. (A) Monolayers of B16-F10 cells were treated with various concentrations $(0,25,50$ and $100 \mu \mathrm{g} / \mathrm{ml})$ of PIO for 24 and $48 \mathrm{~h}$. (B) Quantitative assessment of the number of cells in the denuded zone. The data represent the mean $\pm \mathrm{SE}$ of three independent experiments. ${ }^{*} \mathrm{P}<0.05$ indicates a significant difference from the control.

Effects of PIO on the motility of B16-F10 cells. The effect of PIO on B16-F10 cell migration was determined using the wound-healing assay in which cells were stimulated to migrate by physical wounding cells. As shown in Fig. 2A, when cells were treated with PBS for 24 and $48 \mathrm{~h}$, an apparent and gradual increase of cells in the denuded zone was observed under light microscopy. B16-F10 cells treated with 25,50 and $100 \mu \mathrm{g} / \mathrm{ml}$ of PIO displayed a reduced ability to migrate and fill the wounded area compared with untreated cells. The quantitative data in Fig. 2B revealed that PIO significantly inhibited the migration of B16-F10 cells.

Effect of PIO on migration and invasion of B16-F10 cells. To further evaluate the anti-metastatic activity of PIO, we assessed the inhibition of B16-F10 melanoma migration and invasion by PIO using Transwell assay with polycarbonate filters (pore size, $8 \mu \mathrm{m}$ ) precoated with gelatin or Matrigel. The results indicated that B16-F10 cells moved from the upper
A

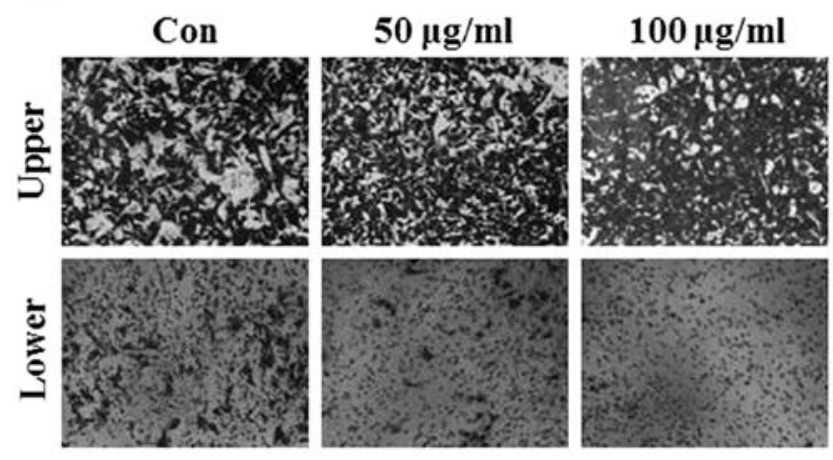

B

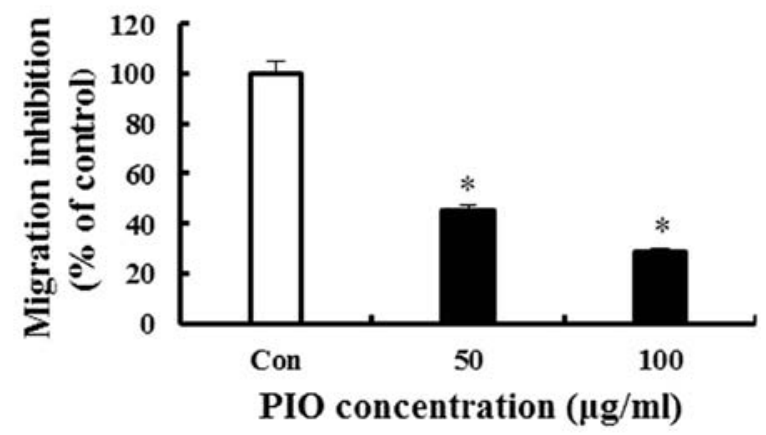

Figure 3. Effect of PIO on the migration of the B16-F10 cells. The B16-F10 cells were treated with various concentrations $(0,50$ and $100 \mu \mathrm{g} / \mathrm{ml})$ of PIO for $24 \mathrm{~h}$. (A) Cell migration was measured for $24 \mathrm{~h}$ in a Transwell chamber with polycarbonate filters (pore size, $8 \mu \mathrm{m}$ ) precoated with gelatin. (B) The migratory ability of B16-F10 cells was quantified by counting the number of migrated cells. Cells were captured using an optical microscope (original magnification, $\mathrm{x} 40$ ). The data represent the mean $\pm \mathrm{SE}$ of three independent experiments. ${ }^{*} \mathrm{P}<0.05$ indicates a significant difference from the control.

chamber to the lower chamber in the absence of PIO (control group), suggesting that B16-F10 melanoma cells can migrate across a Transwell insert precoated with gelatin. PIO at 50 and $100 \mu \mathrm{g} / \mathrm{ml}$ significantly inhibited melanoma cell migration by 56 and $72 \%$, respectively (Fig. 3). As shown in Fig. 4, the results of the invasion assay illustrated that untreated B16-F10 cells moved from the upper to the lower chamber, suggesting that B16-F10 cells can invade through Matrigel-coated Transwell cell culture chambers. However, the addition of PIO to the B16-F10 cells resulted in inhibitory effects on cellular invasion in a concentration-dependent manner. Data in Fig. 4B indicate that 50 and $100 \mu \mathrm{g} / \mathrm{ml}$ PIO significantly inhibited invasion by 31 and $61 \%$, respectively. Thus, these results suggested that PIO effectively reduced melanoma cell migration and invasion.

Effect of PIO on the activities and expression of MMPs of B16-F10 cells. ECM degradation is crucial to cellular invasion, indicating the inevitable involvement of matrix-degrading proteinases (27). Therefore, the effect of PIO on MMP activities was investigated by gelatin-zymography under a condition of serum starvation to clarify the contribution of MMPs to the inhibitory effect of PIO on the invasive ability of cells. As shown in Fig. 5A, gelatin-zymography was used to analyze the effect of PIO on MMP-2 and MMP-9 activities in B16-F10 melanoma cells. MMP-2 and MMP-9 activities were markedly reduced by exposure to $\mathrm{PIO}$ at concentrations of 25,50 , and 


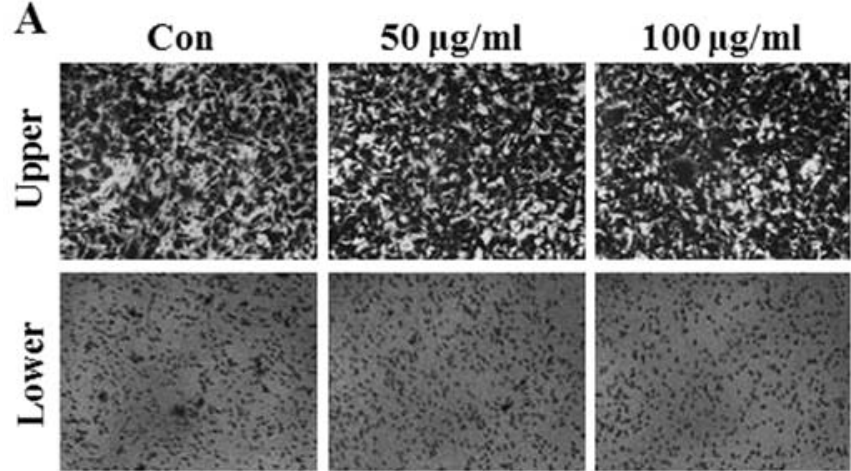

B

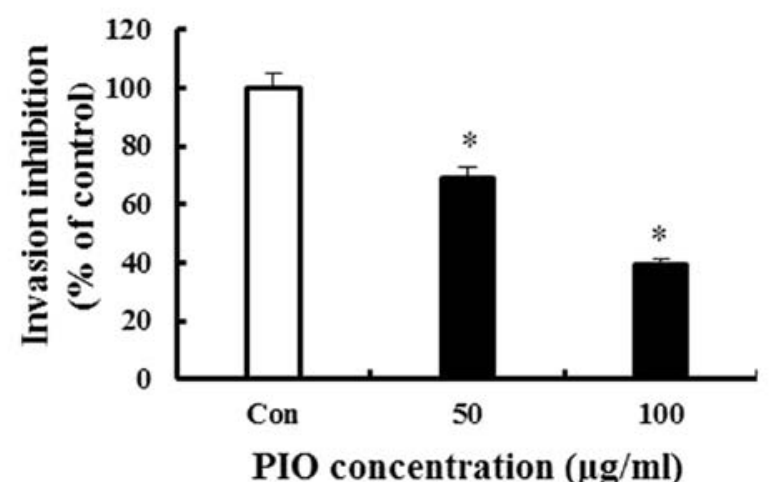

Figure 4. Effect of PIO on the invasiveness of the B16-F10 cells. The B16F10 cells were treated with various concentrations $(0,50$ and $100 \mu \mathrm{g} / \mathrm{ml})$ of PIO for $24 \mathrm{~h}$. (A) Cell invasion was measured after $24 \mathrm{~h}$ in a Transwell chamber with polycarbonate filters (pore size, $8 \mu \mathrm{m}$ ) precoated with Matrigel. (B) The invasiveness of B16-F10 cells was quantified by counting the number of invaded cells. Cells were captured using an optical microscope (original magnification, $x 40$ ). The data represent the mean \pm SE of three independent experiments. ${ }^{*} \mathrm{P}<0.05$ indicates a significant difference from the control.

$100 \mu \mathrm{g} / \mathrm{ml}$ for $24 \mathrm{~h}$. To further understand the effects of PIO on MMP-2 and MMP-9, western blot analysis was performed. As shown in Fig. 5B, PIO inhibited the expression of MMP-2 and MMP-9 in B16-F10 melanoma cells. Therefore, these results indicated that $\mathrm{PIO}$ regulated the expression and activities of MMP-2 and MMP-9.

Effect of PIO on $N F-\kappa B$ nuclear translocation and $C O X-2$ expression levels in B16-F10 cells. Activation of $\mathrm{NF}-\kappa \mathrm{B}$ in metastatic cancer cells is involved in the expression of MMP-2 and MMP-9 (28). COX-2 also affects the expression of MMP-2 and MMP-9 in highly metastatic cancer cells (13). To investigate whether PIO could regulate the NF- $\kappa \mathrm{B}$ signaling pathway in B16-F10 melanoma cells, cells were treated with the indicated concentrations of PIO. The translocation of $\mathrm{NF}-\kappa \mathrm{B}$ and COX-2 expression levels were determined by western blot analysis. As shown in Fig. 6, the total cytosolic $\mathrm{NF}-\kappa \mathrm{B}$ protein levels in B16-F10 cells was increased by PIO treatment compared with that in untreated cells. By contrast, the protein levels of $\mathrm{NF}-\kappa \mathrm{B}$ in the nucleus of B16-F10 cells markedly decreased after PIO treatment compared with the control levels. Moreover, we found that the expression levels of COX-2 in PIO-treated B16-F10 cells were markedly lower than those of the untreated control. These data indicated that PIO inhibited $\mathrm{NF}-\kappa \mathrm{B}$ activation and COX-2 expression in melanoma cancer cells.
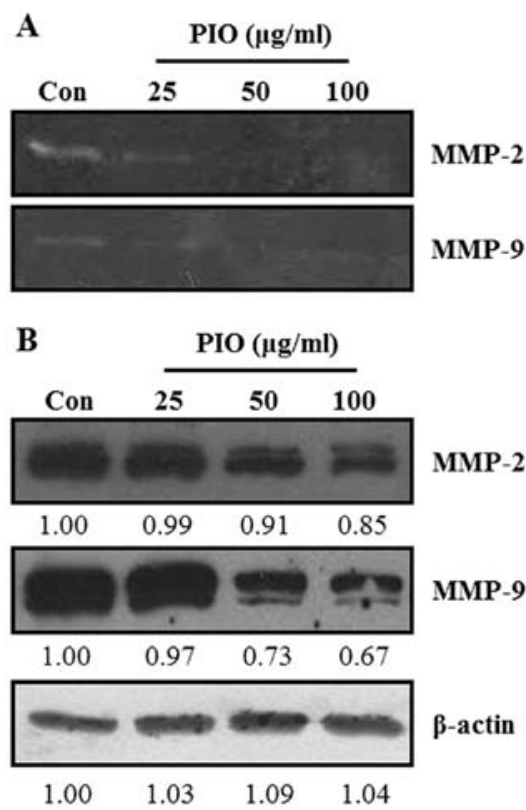

Figure 5. Effect of PIO on the expression and activities of MMP-2 and MMP-9 in the B16-F10 cells. The B16-F10 cells were treated with various concentrations of PIO in serum-free medium for $24 \mathrm{~h}$. (A) The gelatinolytic activities of MMP-2 and MMP-9 were determined by zymography. (B) The expression levels of MMP-2 and MMP-9 were measured by western blot analysis. Equal loading of total proteins in each sample was verified by $\beta$-actin expression.

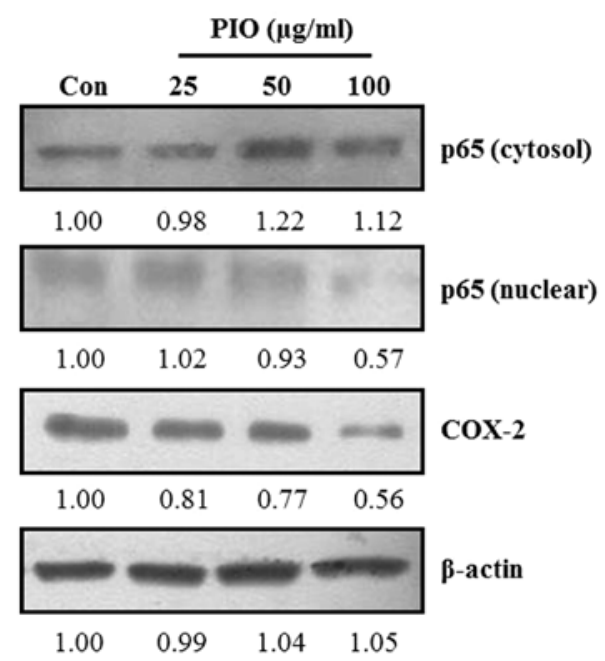

Figure 6. Effect of PIO on the translocation of NF- $\mathrm{BB}$ and COX-2 expression in the B16-F10 cells. The B16-F10 cells were treated with various concentrations of PIO for $24 \mathrm{~h}$. The levels of activated NF- $\mathrm{BB}$ and COX-2 were determined by western blot analysis using a nuclear extraction kit. Equal loading of total proteins in each sample was verified by $\beta$-actin expression.

Effect of PIO on MAPK and Akt signaling pathways in B16-F10 cells. Recent studies reported that MAPK and PI3K/Akt signaling pathways are involved in cancer cell migration and invasion (29). MAPKs and Akt have been demonstrated to be involved in MMP induction in various tumor types (30). To examine whether PIO could regulate MAPK and Akt signaling pathways in B16-F10 melanoma cells, we analyzed the phosphorylation levels of all three MAPKs (ERK, JNK and p38 MAPK) and Akt by western blot analysis using respective anti-phospho MAPK and Akt mAbs in B16-F10 cells after 


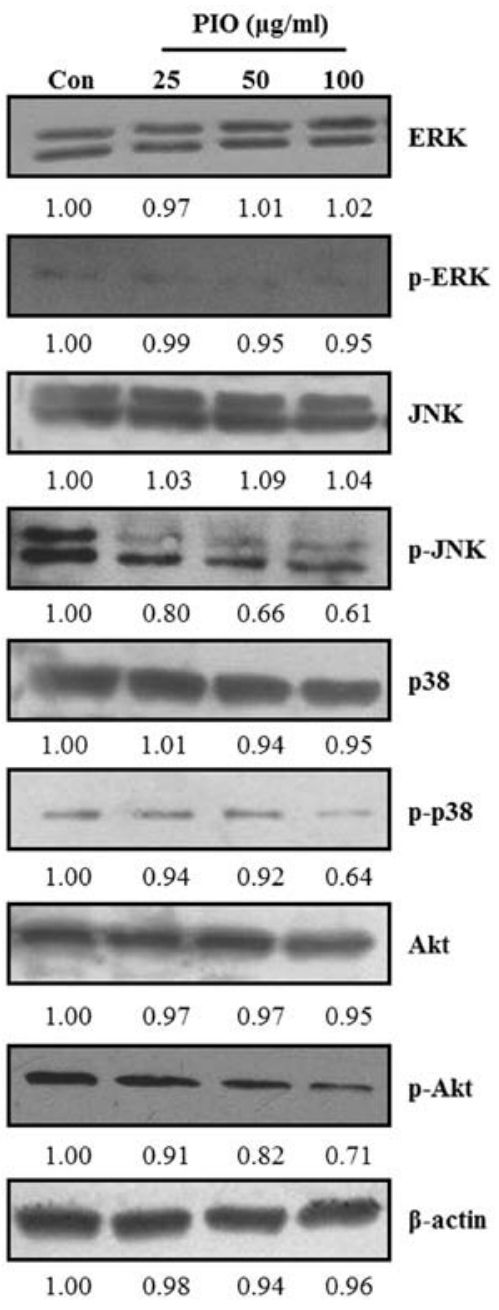

Figure 7. Effect of PIO on Akt and MAPK signaling in the B16-F10 cells. The B16-F10 cells were treated with various concentrations of PIO for $24 \mathrm{~h}$. The levels of activated Akt, ERK, p38 MAPK, and JNK were determined by western blot analysis. Equal loading of total proteins in each sample was verified by $\beta$-actin expression.

treatment with PIO $(25,50$ and $100 \mu \mathrm{g} / \mathrm{ml})$ for $24 \mathrm{~h}$. As shown in Fig. 7, PIO did not affect the expression levels of all three MAPKs and Akt, but PIO suppressed the phosphorylation levels of ERK, JNK, p38 MAPK and Akt in comparison with the findings in the untreated control. In particular, the phosphorylation levels of JNK, p38 MAPK and Akt were highly inhibited by the addition of PIO at concentrations of 50 and $100 \mu \mathrm{g} / \mathrm{ml}$. These data indicated that PIO inhibited the phosphorylation of MAPKs and Akt in melanoma cells.

\section{Discussion}

It is well known that tumor metastasis occurs in many steps including vessel formation, cell attachment, adhesion, migration, invasion and cell proliferation (31). These events are regulated by an extremely complex mechanism. Therefore, considerable attention is focused toward developing agents or drugs that can inhibit metastasis; however, anti-metastatic agents are still lacking. Numerous reports have revealed that the inhibition of MMP expression and/or inhibition of the activities of MMP enzymes can prevent cancer metastasis $(32,33)$. MMP-2 (72-kDa gelatinase A) and MMP-9 (92-kDa gela- tinase B) are involved in the invasive metastatic potential of tumor cells. These MMPs are also associated with COX-2, the activity and expression of which may modulate the expression and activity of MMPs (34). In the present study, we investigated the effects of PIO on the migration and invasion of the highly metastatic B16-F10 mouse melanoma cell line in vitro. Our results from wound healing, migration and invasion assays also demonstrated that PIO inhibited the migration and invasion of B16-F10 cells (Figs. 3 and 4). In addition, the results indicated that PIO can suppress the expression and activities of MMP-2 and MMP-9, which facilitate the degradation of ECM and play important roles in cancer cell migration and invasion (Fig. 5). These findings demonstrated that the anti-metastatic effects of PIO were associated with the inhibition of enzymatic degradation processes in metastatic B16-F10 cells and suggest that PIO may be efficacious at preventing the metastasis of cancer cells. We found that PIO also regulated potential signaling pathways related to the migration and invasion of highly metastatic cancer cells (Fig. 7). PIO inhibited the phosphorylation of MAPKs. The MAPK signaling pathway was found to promote tumor invasion and metastasis in B16-F10 cells. We also found that PIO inhibited the phosphorylation of Akt in B16-F10 cells, indicating that PIO could inhibit the Akt signaling pathway. It was reported that PI3K activation stimulated the downstream target AKT, which is associated with cell invasion. It is well documented that the PI3K-Akt pathway plays important roles in the invasive properties of cancer cells (35). Previous reports demonstrated that the MMP-2 and MMP-9 promoter has several transcription factor-binding motifs including those for NF- $\kappa \mathrm{B}$ and AP-1. Multiple pathways leading to the activation of NF- $\kappa \mathrm{B}$ and AP-1 binding factors in tumor cells may contribute to MMP-2 and MMP-9 transcription and enhance invasiveness (36). In the present study, we found that PIO regulated $\mathrm{NF}-\kappa \mathrm{B}$ translocation from the cytosol to the nucleus and the expression and activities of MMP-2 and MMP-9 in B16-F10 cells in vitro. Thus, PIO may suppress the mRNA expression of MMP-2 and MMP-9 via RNA transcription factors. These findings indicate that PIO strongly inhibits the metastasis of B16-F10 cells by inhibiting NF- $\kappa$ B translocation. Then, PIO reduces the transcription and translation of MMP-2 and MMP-9, thereby decreasing the activities of MMP-2 and MMP-9. These results suggest that PIO inhibited the expression and activities of MMP-2 and MMP-9 by inhibiting the NF- $\kappa \mathrm{B}$ signaling pathway. Evidence indicates that COX-2 plays an important role in the carcinogenesis and progression of cancer, and the induction of MMP-2 and MMP-9 expression may be a mechanism by which COX-2 promotes the development and metastasis of cancer (37). The present study demonstrated that PIO markedly reduced in vitro COX-2, MMP-2 and MMP-9 expression in B16-F10 cells. Furthermore, migration and invasion data confirmed that PIO significantly inhibited the migration and invasion of B16-F10 cells. In conclusion, MMPs play an important role in tumor metastasis. Therefore, it is well established that MMP gene expression and enzymatic activity are early targets for preventing cancer metastasis. The present study suggested that PIO inhibits the migration and invasion of highly metastatic B16-F10 cells, which may mainly result from the PIO-mediated inhibition of the expression and activities of MMP-2 and MMP-9 via the suppression of Akt, MAPKs NF- $\kappa \mathrm{B}$ and COX-2 signaling pathways. 


\section{Acknowledgements}

The present study was supported by the Basic Science Research Program through the National Research Foundation of Korea (NRF) funded by the Ministry of Education (NRF2011-0011522).

\section{References}

1. Monks NR, Biswas DK and Pardee AB: Blocking anti-apoptosis as a strategy for cancer chemotherapy: NF- $\mathrm{B}$ as a target. J Cell Biochem 92: 646-650, 2004.

2. Walsh V and Goodman J: Cancer chemotherapy, biodiversity, public and private property: the case of the anti-cancer drug taxol. Soc Sci Med 49: 1215-1225, 1999.

3. Rosenberg SA and Dudley ME: Cancer regression in patients with metastatic melanoma after the transfer of autologous antitumor lymphocytes. Proc Natl Acad Sci USA 101 (Suppl 2): S14639-S14645, 2004.

4. Solari N, Acquati M, Queirolo P, et al: Primary melanoma of the esophagus with non-metastatic dark lymph nodes in a female breast cancer patient. Anticancer Res 27: 2849-2853, 2007.

5. Han JY, Kim HS, Lee SH, Park WS, Lee JY and Yoo NJ: Immunohistochemical expression of integrins and extracellular matrix proteins in non-small cell lung cancer: correlation with lymph node metastasis. Lung Cancer 41: 65-70, 2003.

6. Ichikawa $\mathrm{Y}$, Ishikawa $\mathrm{T}$, Tanaka K, Togo $\mathrm{S}$ and Shimada $\mathrm{H}$ Extracellular matrix degradation enzymes: important factors in liver metastasis of colorectal cancer and good targets for anticancer metastatic therapy. Nihon Geka Gakkai Zasshi 102: 376-380, 2001 (In Japanese).

7. Liao J, Schneider A, Datta NS and McCauley LK: Extracellular calcium as a candidate mediator of prostate cancer skeletal metastasis. Cancer Res 66: 9065-9073, 2006.

8. Santos MC, de Souza AP, Gerlach RF, Trevilatto PC, ScarelCaminaga RM and Line SR: Inhibition of human pulpal gelatinases (MMP-2 and MMP-9) by zinc oxide cements. J Oral Rehabil 31: 660-664, 2004.

9. Chien CS, Shen KH, Huang JS, Ko SC and Shih YW: Antimetastatic potential of fisetin involves inactivation of the $\mathrm{PI} 3 \mathrm{~K} / \mathrm{Akt}$ and $\mathrm{JNK}$ signaling pathways with downregulation of MMP-2/9 expressions in prostate cancer PC-3 cells. Mol Cell Biochem 333: 169-180, 2010.

10. Grimm T, Chovanova Z, Muchova J, et al: Inhibition of NF- $\kappa B$ activation and MMP-9 secretion by plasma of human volunteers after ingestion of maritime pine bark extract (Pycnogenol). J Inflamm 3: 1, 2006.

11. Ispanovic E and Haas TL: JNK and PI3K differentially regulate MMP-2 and MT1-MMP mRNA and protein in response to actin cytoskeleton reorganization in endothelial cells. Am J Physiol Cell Physiol 291: C579-C588, 2006.

12. Zhang HW, Wang X, Zong ZH, Huo X and Zhang Q: AP-1 inhibits expression of MMP-2/9 and its effects on rat smooth muscle cells. J Surg Res 157: e31-e37, 2009.

13. Cui D, Zhang X and Fu Y: Expressions of COX-2 and MMP-2 in nasopharyngeal carcinoma and the their relationship with lymph node metastasis. Lin Chung Er Bi Yan Hou Tou Jing Wai Ke Za Zhi 22: 692-694, 2008 (In Chinese).

14. Yildirim Y, Ozyilkan O, Bilezikci B, Akcali Z and Haberal M: Lack of influence of cyclooxygenese-2 expression in hepatocellular carcinomas on patient survival. Asian Pac J Cancer Prev 9: 295-298, 2008.

15. Burczyk J, Gawron A, Slotwinska M, Smietana B and Terminska K: Antimitotic activity of aqueous extracts of Inonotus obliquus. Boll Chim Farm 135: 306-309, 1996.

16. Kim YO, Han SB, Lee HW, et al: Immuno-stimulating effect of the endo-polysaccharide produced by submerged culture of Inonotus obliquus. Life Sci 77: 2438-2456, 2005.

17. Kim YO, Park HW, Kim JH, Lee JY, Moon SH and Shin CS Anti-cancer effect and structural characterization of endopolysaccharide from cultivated mycelia of Inonotus obliquus. Life Sci 79: 72-80, 2006.
18. Sun JE, Ao ZH, Lu ZM, et al: Antihyperglycemic and antilipidperoxidative effects of dry matter of culture broth of Inonotus obliquus in submerged culture on normal and alloxan-diabetes mice. J Ethnopharmacol 118: 7-13, 2008.

19. Liang L, Zhang $\mathrm{Z}$ and Wang $\mathrm{H}$ : Antioxidant activities of extracts and subfractions from Inonotus Obliquus. Int J Food Sci Nutr 60 (Suppl 2): 175-184, 2009.

20. Van Q, Nayak BN, Reimer M, Jones PJ, Fulcher RG and Rempel CB: Anti-inflammatory effect of Inonotus obliquus, Polygala senega L., and Viburnum trilobum in a cell screening assay. J Ethnopharmacol 125: 487-493, 2009.

21. Lee JS, Kwon JS, Won DP, et al: Study of macrophage activation and structural characteristics of purified polysaccharide from the fruiting body of Cordyceps militaris. J Microbiol Biotechnol 20: 1053-1060, 2010.

22. Won DP, Lee JS, Kwon DS, Lee KE, Shin WC and Hong EK: Immunostimulating activity by polysaccharides isolated from fruiting body of Inonotus obliquus. Mol Cells 31: 165-173, 2011.

23. Rodriguez LG, Wu X and Guan JL: Wound-healing assay. Methods Mol Biol 294: 23-29, 2005.

24. Kramer N, Walzl A, Unger C, et al: In vitro cell migration and invasion assays. Mutat Res 752: 10-24, 2013.

25. George SJ and Johnson JL: In situ zymography. Methods Mol Biol 151: 411-415, 2001

26. Hawkes SP, Li H and Taniguchi GT: Zymography and reverse zymography for detecting MMPs, and TIMPs. Methods Mol Biol 151: 399-410, 2001.

27. Artym VV, Yamada KM and Mueller SC: ECM degradation assays for analyzing local cell invasion. Methods Mol Biol 522: 211-219, 2009.

28. Philip S, Bulbule A and Kundu GC: Matrix metalloproteinase-2: mechanism and regulation of NF-kappaB-mediated activation and its role in cell motility and ECM-invasion. Glycoconj $\mathrm{J} 21$ : 429-441, 2004

29. Hour MJ, Tsai SC, Wu HC, et al: Antitumor effects of the novel quinazolinone MJ-33: Inhibition of metastasis through the MAPK, AKT, NF- $\kappa$ B and AP-1 signaling pathways in DU145 human prostate cancer cells. Int J Oncol 41: 1513-1519, 2012.

30. Cho SJ, Chae MJ, Shin BK, Kim HK and Kim A: Akt- and MAPK-mediated activation and secretion of MMP-9 into stroma in breast cancer cells upon heregulin treatment. Mol Med Rep 1: 83-88, 2008.

31. Bartolome RA, Barderas R, Torres S, et al: Cadherin-17 interacts with $\alpha 2 \beta 1$ integrin to regulate cell proliferation and adhesion in colorectal cancer cells causing liver metastasis. Oncogene: April 22, 2013 (Epub ahead of print).

32. Cheng Y, Dong Q, Sun LR, Yang CM and Jiang BX: Correlation between expression of MMP-2, MMP-9, TIMP-2, TIMP-1 and metastasis of neuroblastoma. Zhonghua Zhong Liu Za Zhi 27: 164-166, 2005 (In Chinese).

33. Taras D, Blanc JF, Rullier A, et al: Pravastatin reduces lung metastasis of rat hepatocellular carcinoma via a coordinated decrease of MMP expression and activity. J Hepatol 46: 69-76, 2007.

34. Yoon HY, Lee EG, Lee H, et al: Kaempferol inhibits IL-1 $\beta$ induced proliferation of rheumatoid arthritis synovial fibroblasts and the production of COX-2, PGE2 and MMPs. Int J Mol Med 32: 971-977, 2013.

35. Shukla S, Maclennan GT, Hartman DJ, Fu P, Resnick MI and Gupta S: Activation of PI3K-Akt signaling pathway promotes prostate cancer cell invasion. Int J Cancer 121: 1424-1432, 2007.

36. Park SY, Kim YH, Kim Y and Lee SJ: Frondoside A has an antiinvasive effect by inhibiting TPA-induced MMP-9 activation via $\mathrm{NF}-\kappa \mathrm{B}$ and AP-1 signaling in human breast cancer cells. Int J Oncol 41: 933-940, 2012.

37. Lipari L, Mauro A, Gallina S, et al: Expression of gelatinases (MMP-2, MMP-9) and cyclooxygenases (COX-1, COX-2) in some benign salivary gland tumors. Int J Immunopathol Pharmacol 25: 107-115, 2012. 